\title{
HEURISTIC THINKING ON DATA VISUALIZATION BASED ON DASHBOARD CASE STUDIES AT NATIONAL HOSPITAL SURABAYA
}

\author{
Raden Hendarto Oktavianus ${ }^{1}$, Dedhy Sulistiawan ${ }^{2}$ \\ ${ }^{1,2}$ Magister Akuntansi, Fakultas Bisnis dan Ekonomika, Universitas Surabaya
}

\begin{tabular}{l}
\hline \hline Article Info \\
\hline Article history: \\
Received 29 April, 2021 \\
Revised 09 June, 2021 \\
Accepted 09 June, 2021 \\
\hline
\end{tabular}

\section{Keywords:}

Data visualization

Information

Dashboard

Bias

Heuristic thinking

\begin{abstract}
Dashboard-based data visualization has various information is an option for presenting data is expected to support decision making. The ease of the dashboard isn't perfect, but it also has weakness. The nature of heuristic thinking makes users behave inconsistent with the rational decision-making process tobe an important issue. This study was conducted to explain the heuristic thinking behavior phenomenon from dashboard-based data visualization in the decision-making process. A qualitative approach is used with procedures and data collection based on interview techniques, observation and literature study. Data were observed from the National Hospital, Surabaya. The result is there is a bias in seeing data in a visual form, someone will tend to simplify the decision-making process. The contribution of this study is heuristic thinking on dashboard-based data visualization which can lead users to make irrational decisions.
\end{abstract}

This is an open access article under the $\underline{C C B Y-S A}$ license.

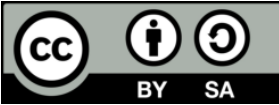

\section{Corresponding Author:}

Raden Hendarto Oktavianus

Magister Akuntansi, Fakultas Bisnis dan Ekonomika

Universitas Surabaya

Email: hendarto.oktavianus@gmail.com

(C) Raden Hendarto Oktavianus and Dedhy Sulistiawan 2021

\section{Introduction}

Technological developments allow all activities of human life more easy and simply. Digitazion computer technology with digitization create an information system has been used in almost all fields. This information system assists its users in carrying out daily business processes. The information system converts the manual recording process into the computer process. It's minimize errors that occur due to manual processes. The use of this information system also produce easily accessed report without any restrictions. The information system, with its excellence, has become an important part in a company to help management in the decisionsupport process. The originator of the idea of bias and heuristics in [1], argues that many decisions based on beliefs about the possibility of uncertain happen, and people rely on several heuristic that reduce the decisionmaking. Therefore, a decision must be based on the data and information collected. It is the information system to helps the process decision-making be easier. Information is a data process be more useful and meaningful to the recipient [2]. Information is also processed data to be more useful, which reduces uncertainty in the decision-making process about a situation [3]. Companies to be able to produce information, it;s necessary the system to collect, process, and store data useful for the decision-making process. The collected data will be useful for management in determining future strategic steps.

As in [4] there are 3 activities will be processed by information system and used by the company in making decisions, controlling operational activities, analyzing problems and forming a product and service. The era of 
big data today, the presentation of information can be done in several ways, especially the presentation of information using information systems. The data presented must be simple, clear so it is easy to read. The presentation of the data is also intended till the readers can easily understand, then it will be presented and assesst or compare. Successful organizations must be able to transform data into efficient information into knowledge or things to be followed up [5]. In order to provide a meaningful picture, the data must be presented in a systematic manner and for analysis purposes. It can be presented in the form of written reports, or visuals such as tables or diagrams.

Data visualization is important because the human brain processes visual information more easily than numbers. Good data visualization can help the lay public to understand complex data. "Data is not numbers only, but also a source of information. Data must be made attractive so that any information in the data can be conveyed to the public properly," said Damar Aji Pramudita, a programmer in the Business Intelligence division of the digital decacorn company, GoJek. He assessed Good visualization is the key to making the audience better understand the message behind the data [6].

Data visualization dashboard-based is an option for organizations to make decisions based on data and information. As in [1] states that as a tool, dashboard-based data visualization is expected to improve decision making by strengthening human cognitive systems and utilizing human perceptual abilities. Dashboard is one of the business intelligence (BI) can facilitate management tasks in monitoring, checking and controlling [7]. Thus dashboard is a solution to provide information for management from previously inputted processing data in an information system, a way of data visualization. The information available in dashboard can be used to support operational decisions in running activities or for decisions in the future, leading to improvements in operational activities to suit company goals. Dashboard is aimed at extending human visual analytics which helps the human visual system to better interact with data by combining, searching or sorting relevant information [8].

Dashboard system has function in presenting information to make easier for users to view data and information, sometimes also provides a bad side for its users. In addition to providing benefits, this system can also make users have a heuristic thinking characteristic that makes users behave and make decisions irrationally. As in [1], the heuristic nature can cause fatal or severe errors in decision making and cause decision biases. The ease information is obtained make someone conclude easily without deep-understand, and also bring up biases make someone behave wrong and even in making decisions. Heuristics are "rules of practical", through assumption, intuitive judgments or common sense, in [9], finding that a person will be a heuristic when he/she tired of seeing a lot of information.

The role of National hospitals as health services also use various forms of data presentation. Data formed in tables and graphs is also used to help decide management actions to support operational activities. Data visualization is also formed in dashboard so that it is easy to analyze and make decisions. Data visualization and information in health services in hospitals is very useful for the purposes of reporting, monitoring and evaluating program performance, as well as coordination between departments within the hospital. For example, the medical records department whose task to collect patient medical record data uses data visualization in its report every month to the health office which. Reporting for management also uses data visualization to make the management easier to see information about the condition of the hospital, such as: in terms of income, debt position, etc.

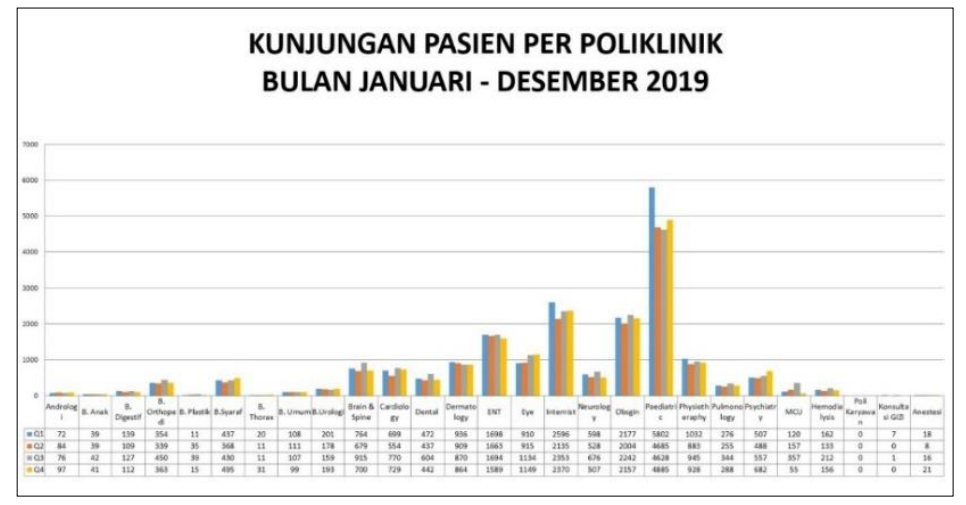

Gambar 1. Grafik kunjungan pasien per poliklinik 
As example, the graph of patient visits per polyclinic in January to December 2019, this data is used to see what polyclinics will be visited, such as the pediatric polyclinic or images occupy the first rank,.In general this graph can also be used to determine management decisions, such as promote or effort to increase the number of visits to other polyclinics, thus increasing hospital income.

This study will explore depth-nformation about the use of dashboards at the National Hospital to see the effect of using dashboard-based data visualization and heuristic thinking bias and it make on decision making and conclude the effect oft the effect of heuristic thinking in dashboard-based decision making.

\section{Research Method}

This research uses interpretivism paradigm, it means to explains the meaning of the subjective context of social action and has multidimensional truth. This study is about the phenomena of human behavior in decision making by using dashboard. The result of the study use a paradigm derived from sources as the object of research and become important information for researchers and other researchers related to behavioral analysis in dashboard-based operational decision-making process. The stages of this study are as follows:

\subsection{Data collection technique}

This study uses a qualitative approach to understand the phenomena experienced by the research subjects. The type of research is a case study by conducting an investigation to provide the description of a particular subject. Data were collected by researchers using document analysis, observation and interview methods. Data will be obtained from companies that use dashboards in their business processes in making decisions or reporting to monitor the current business situation.

1) Document analysis: Documents are resources used to complement research. It might be written sources, films, pictures, and monumental works, that provide information for the research process [10]. This study will do a lot of analyzing data, it's not only physical documents but also electronic documents. It is dashboard analysis which is used to assist reporting activities and decision-making tools on the research object.

2) Observation: The observation technique is the observation of the researcher towards the object of research, the observation method can produce more detailed data about the behavior (subject), thing or events (objects) than the interview method [11]. Observation is data collection tool was conducted by systematically the phenomenon occurs [12]. Researchers will make observations by observing the dashboard used periodically and then record aspects of user behavior after seeing dashboard, especially those related to decision making and the completeness of the data contained on dashboard.

3) Interview: The technique of collecting data by interview is a way of collecting data needed to answer the research problems [13]. Interview is structure or unstructure conversation conducted by individuals or groups through face-to-face, telephone, or online [14]. Researcher will conduct interviews with everyone in every part of the business unit who uses the dashboard in their daily operations. Researchers will conduct an interview process with parties related to the dashboard or dashboard users directly in their operational activities.

\subsection{Methods}

In this study, after the data and information were collected, the researchers conducted an analysis of the data and information obtained by referring to the research questions that have been prepared to answer the main questions in this study. The research question is "How is the effect of heuristic thinking bias in using the dashboard as a way of visualization data and information in the decision-making process?" and the following sub-questions related to the main research questions:

1) Sub-Question 1: Why is the visual data presentation technique more attractive and be option in decision making, especially the presentation of data visualization in dashboard information?

2) Sub Question 2: What behavior arises when making decisions using data visualization in dashboard information?

3) Sub Question 3: Why does heuristic thinking occur when saw overloaded information?

4) Sub-Question 4: How does heuristic thinking influence decision making using dashboard-based data visualization? 


\section{Results and Discussion}

Researchers have collected data to answer compiled research questions by interviewing with several respondents at the National Hospital, then observating in departments that use dashboard-based data visualization and seeing biases with a heuristic focus and also conducted document studies through journals, papers, or other research to complement the research questions. Researchers also conducted interviews with respondents outside the research object in order to see or find more detailed information about a person's behavior when viewing visual or dashboard information related to make decision and to know the heuristic thinking.

The data collected during interviews and observations on respondents help the researchers to answer the research questions of this study. Researchers conducted interviews with 7 people who used data visualization and dashboards in their work. Of the 7 people, 4 people came from the National Hospital and 3 people came from outside the National Hospital. Researchers also conducted interviews with people outside the National Hospital in order to prove the views and behavior of respondents in response to data visualization and dashboards.

Information in writing form. From the data collected from interviews, the researcher found that the respondents felt the information in writing form was uncomfortable or difficult to see, had to read one by one so that it took a long time to see the information. Respondents sometimes have to be quick to view information, and people who don't like or lazy to read will waste the time. beside that, the respondents also felt that written information could not be immediately understood and in some respondents it was proven that there was an immediate misperception, indicating error in reading written information could occur. Respondents have to read the whole thing first before they can understand it, cannot be fast, it is impractical. There were even respondents who immediately stated that they were people who did not like reading and it was better if they looked at numbers, so they could be analyzed immediately.

"For me personally, I admit that I don't like reading, I better see it in numbers, so I can immediately analyze it," said Mrs. Didhin Dwi.

"I think Data in writing form is impractical. I have to read one by one, it takes a long time, it becomes less informative, sometimes I need to quickly see information, if it is written like this it can be a waste of my time", according to Mr.Yudi Indranata.

The respondents also stated that the data was written in writing shown by the researcher, the respondents could not conclude or even make decisions, they could not take action. Respondents stated that they were bored in seeing written information and if used to decide they could not, because they did not show clear information, if they wanted to decide, other supporting data was needed.

"I cannot conclude or decide, I also cannot take action by seeing the information in this paper, the information is not clear, I have to see other supporting data. I am tired of seeing the writing, "said Mrs. Cynthia Aprilia.

Based on data collected above, the researchers concluded that the information in writing form is not informative, because to see or read it takes a long time, it is necessary to read one by one, especially if the written information is very large, making it impractical. In fact, some respondents had reading errors and misunderstanding of the information presented by the researchers in the interview.

Information in tables and graphs form. From the interviews have been conducted, the respondents feel that they prefer to present information in tables and graphs form. They felt information can be seen immediately, can even directly make comparisons, it is faster and easier to see information, and can even immediately make decisions when writing to try to ask about what actions related the data.

"I like this form of information, I can immediately see to make comparisons between the data, it's faster and easier to see the information," said Mrs. Didhin Dwi.

Information in tables and graphs form according to respondents is easier to understand, because it immediately shows the information according to the information, otherwise the writing can be mistaken. Information on tables and graphs without looking at the numbers can be immediately seen from the shape of the lines, so that 
the trend can be seen immediately. Someone will be able to focus immediately, more quickly and effectively in seeing the information presented.

"Forms like this are easier to understand, immediately show the information exactly according to the explanation, if the writing is misperception, this one is more informative without looking at the numbers, you can see the trend. I am more focused, faster, more effective than seeing one by one, " according to Mr. Ronald Louhenapessy.

"Tables and graphs form are easier to see and read, I can immediately see trends quickly, I more focused and choose to see information in this form, especially in my work it takes a short time to decide", according to Mr. John.

"For me in the marketing department, I chose the display of information in this form, I can immediately see and can evaluate to make innovations if something lack, so I can immediately decide on the next action", according to Merry Khirstianti.

The information in the form of tables and graphs according to respondents can be easily understood because it is more pleasing to the eye, and even helps respondents in making decisions. There are also respondents feel information in tables and graphs form is not sufficiently helpful in making decisions, respondents still need other supporting data that strengthens the information presented in tables and graphs, because to be able to decide respondents feel they need analyse first before making a decision.

"The form of tables and graphs is more pleasing to the eye, more supportive of decision making than writing, but I still need a lot of analysis and explanation, not only by looking at tables and graphs, but sometimes need other data to convince me," according to Cynthia Aprilia.

Based on data has been collected from the respondents' opinions, it can be concluded that the respondents prefer to see the information presented in tables and graphs form, because it is easier to read, can immediately see trends, the information presented is more informative than written information. It will be more focused, faster and more effective in viewing information. Decision making can also be done by looking at the information in tables and graphs form, but some respondents also need additional data to help analyse before making further decisions or actions after seeing this information in tables and graphs form. Respondents prefer information in visual data form.

Information in Visual data form. This information is more attractive and easy to read. The respondents all chose to view information in visual data form, tables and graphs form. It provides information conclusions, is more clearly readable and easy to understand, rather than having to see the writing one by one. When asked to take action, it can be done quickly because the data is clearly presented. This proves that data in visual form has an advantage in conveying information. Visual representations of data allow individuals to process information more efficiently than text, and even transform complex information to guide human behavior more efficiently. As in [15] in his research The Development of Heuristics for Evaluation of Dashboard Visualizations. Merill \& Dowding said that visual data is an effective way of conveying information, especially on the health industry. Today's existing computer capabilities and reports in the vast and large world of health are accompanied by the ability of computers to collect data, which in turn produce useful information for decision making.

Visual data in the dashboard. From the interviews conducted, researchers got information that most respondents stated that the dashboard was very informative in presenting information. The wide range of data collected from various into one view provides benefits to users, all data is presented clearly, the dashboard can immediately show the actual conditions, thus helping in decision making even though you still have to see additional information outside the existing dashboard.

“... It really helps me in seeing the information, everything has been presented clearly, showing the real conditions that exist in real time. It helps me make decisions, but sometimes I still need to see additional information outside the dashboard itself, " according to Mr. John.

Data in the form of visuals on the dashboard can also have risks. It can make someone experience heuristic thinking, someone has a tendency to simplify the process in making decisions, as if "underestimating", because the data is already in sight. Through interviews and observations from several respondents, it can be seen that 
there is fatigue in viewing information on the dashboard which contains a lot of visual data, so that the respondent immediately concludes. It can be concluded that with the information overload on the dashboard, it seems as if someone is "easy" to see the information.

"This dashboard is complicated, with lots of colors and data, you have to look carefully. It's easier for sure, because there's a lot of data and a lot of indicators that can't be simple in presenting it too," according to Mrs. Cynthia.

For respondents, the information presented in the dashboard cannot be directly used for decision making. There is also a lot of information with various indicators on the dashboard, it also requires accuracy in reading the information in it.

Confirmation by other way is required. From the interviews and observations made, the researchers get information that all respondents still need confirmation in other ways when they want to make decisions after seeing the information on the dashboard, as has been conveyed in the explanations and interview scripts shown above. Researchers provide an analogy with a car dashboard to help respondents understand the dashboard. When the battery indicator on the car dashboard lights up, what will the respondent do?, some respondents answered that they first checked why the battery indicator could turn on by taking various actions to ascertain whether the battery was damaged or needed to be replaced or just needed to leave the car for a moment, and some respondents also had to immediately answered that the car battery was damaged, here it can be seen that there is a bias experienced by the respondent. While data visualizations can be very useful, they may be complex and difficult to interpret and understand. The complexity of visualizations can range from data-poor, informal infographics for the general audience to complex, rigorous scientific visualization aimed at scholars [16]. Although visual data is very useful, sometimes the information presented is very complex and difficult to interpret and understand. The complexity of the visualization can range from incomplete data, infographic displays to complex scientific visualization displays. Therefore, further analysis or confirmation is needed to ensure that the information have seen is more complete and really useful for decision making.

"The dashboard helps in displaying data and information, it is very helpful, but if it used to take the next step, I still need help, or see other supporting data, before I decide, I am afraid to take the wrong action", according to Mr. John.

"I still need additional data to complements the information on the dashboard, because I was wrong before, so I am careful with the completeness of the information I have," according to Mr.Yudi Indranata.

"I can't be 100\% sure to make a decision, because the data presented is not necessarily the data I need, it needs to be confirmed in other ways", according to Mrs. Cynthia Aprilia.

"Just seeing, I can't determine directly, other data is needed as comparison and evaluation, the dashboard also needs to be accompanied by additional data, it cannot be separated", according to Mr. Huntoro Irwan.

Bias. Researchers conducted interviews and observations to see the behavior of respondents and when saw large and extensive information in dashboard-based visual data form. Almost all of the respondents were bias when they saw information in visuals data form presented by the researcher, either directly or indirectly. There were some information related to bias that had been experienced. by respondents. One respondent had made a mistake in viewing information from the dashboard. In the middle of a short time, he had to read the information and the situation is rushed, without any in-depth confirmation immediately conclude it. The other respondents were also seen by the researcher when presenting the data tables and graphs and then asked to conclude, the respondents immediately concluded.

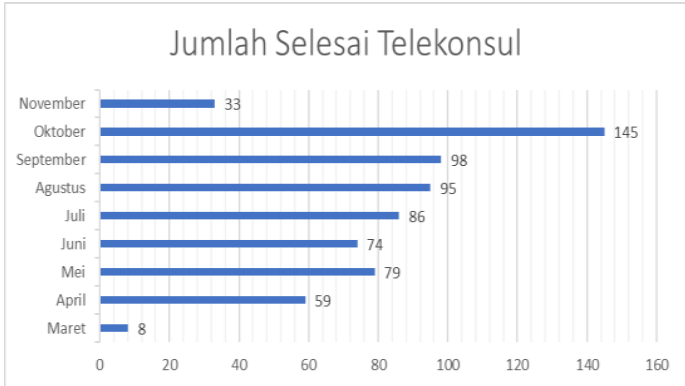

Gambar 2. Grafik jumlah selesai telekonsultasi. 
The respondents were given one of the displays on the teleconsultation application dashboard at the National Hospital, the researchers asked whether October 2020 was the month with the most teleconsultations or no, the respondent answered "yes" that month the most teleconsultations. Respondents did not see other data shown by the researcher during the interview process. The next display is the display of canceling teleconsultation, meaning that the patient has made an appointment with the doctor but canceled it. When viewed and analyzed, October did receive the most teleconsultations, but there were also the most cancellations during the application's use. This proves that in terms of income, October 2020 did not provide a good income compared to the previous months. Heuristics arise when a person looks in a hurry, and tries to convince himself that what he sees is true.

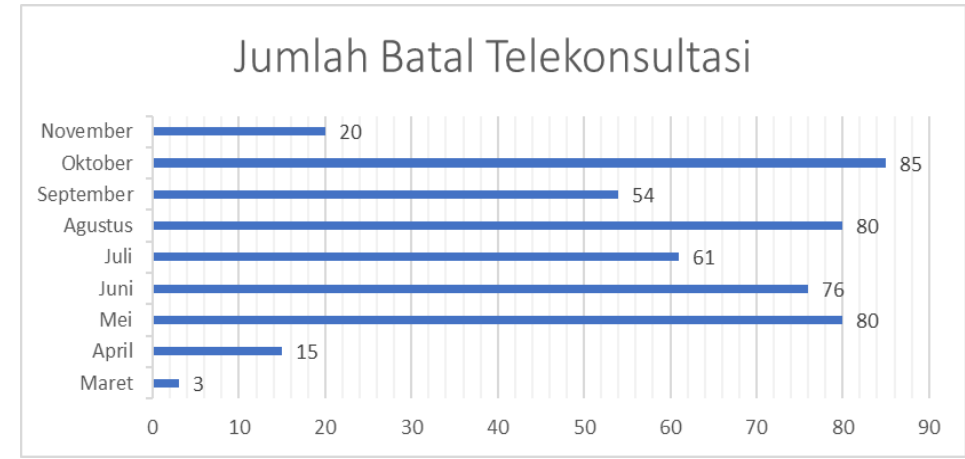

Gambar 3. Grafik jumlah batal telekonsultasi.

Through interviews and observations conducted by researchers with respondents at the National Hospital and outside of the National Hospital, it can be concluded that data visualization is an option in viewing information, the ease and speed of users accessing information in visual form is an advantage and can help in the process in decision-making. This advantage is not enough when someone uses visual data, other supporting data is needed before taking an action or decision. Heuristic thinking emerged in the majority of respondents who proved that bias always appeared when someone saw extensive information or was overloaded in seeing information, so that the respondents immediately decided without considering other data.

Through observations of the visual data used by Mrs. Didhin Dwi, it was found that heuristic characteristics resulted in reporting errors. An ER examination on one of the data in the ER department, before the translation, a nominal amount is stated each month as a report on the number of emergency room visits which means emergency cases, from January to October 2020. This report has been seen by the management as a final report on the number of visits the emergency department in mapping emergency care cases handled by the National Hospital. However, several months passed and after being checked again, it turned out that the patient's visit to the emergency department during this pandemic, not only for emergency cases but also for patients who only came to the hospital to check themselves from exposure to the COVID-19 virus, namely by antibody serological tests and swab tests or PCR tests, so that the total visit patient reports not only consist of emergency cases but also COVID-19 examinations, which must be separate reports in order to calculate the number of COVID-19 examinations and emergency cases that must be reported to the relevant agency. In order to avoid the heuristic nature, or to be too hasty in reading and concluding information, a patient category was separated into the emergency room. For information, National Hospital receives a self-examination of COVID-19, both antibody serology tests and PCR swabs, through the laboratory unit, patients can go directly to the laboratory area and through the emergency department or IGD.

This study has implications for accounting research and also on information systems research that every user of data visualization, especially dashboard-based data visualization, should be careful with the ease of viewing the information presented. Confirmation and consideration are needed before making decisions, thereby reducing the possibility of heuristic thinking bias that can make users behave and make decisions irrationally.

\section{Conclusion}

This study has been conducted to find the answers from the research questions. The data collected from the data collection process resulted in the following conclusions: 
The visual data form is more attractive to respondents than writing form, the presentation of visual information for the respondents was considered to be faster in conveying information, faster to read, practical and easy to understand, very informative. Written information, apart from being uninformative and flawed, on the other hand, can sometimes also be useful to complement visual information.

There is bias in viewing information in visual data form on the dashboard. Almost all respondents who were the object of this study experienced bias, overconfidence and availability bias, both in viewing information and bias in deciding. It is proven that much information in viewing is a threat to users of visual data form on the dashboard. Therefore, confirmations and supporting data is needed to avoid this bias.

A lot of information in one display, especially visual information, will make the readers of the information tired in seeing the information and will become a threat to users of visual data form on dashboard. Data visualization has risks that can make someone experience heuristic thinking, so that it tends to simplify the decision-making process, because it is trivial, data and information are readily available in front of the eye, do not require "effort", do not require excessive effort, so that we immediately conclude without any confirmation or consideration in viewing the information.

The dashboard system has function in presenting information to makes easier for users to view data and information, it has been proven to be a bad side for its users, the emergence of heuristic characteristics makes users behave and make decisions irrationally. The information is obtained easily, on the other hand, it will make someone conclude easily without understanding it deeply, making someone wrong in deed and wrong in making decisions.

\section{References}

[1] K. Bergram and B. Ochan, "Data-driven Biased Decision-making? Exploring the landscape between dashboards, visualization literacy and decision bias," p. 67, 2018.

[2] J. Hutahaean, Konsep Sistem Informasi. 2014.

[3] A. Elisabet Yunaeti and R. Irviani, Pengantar Sistem Informasi. Yogyakarta: Ani, 2017.

[4] K. C. Laudon and J. P. Laudon, Management Information Systems Managing The digital Firm Thirteen Edition Global Edition (SIB). 2014.

[5] B. Daniel, N. Herb, B. Paul, and I. Amy, "Big data analytics: transforming data to action," Bus. Process Manag. J., vol. 23, no. 3, pp. 703-720, Jan. 2017, doi: 10.1108/BPMJ-03-2016-0056.

[6] F. E. CHRISTY, "Visualisasi Data, Mengubah Lautan Angka Menjadi Sumber Informasi," tekno.tempo.co, 2019. https://tekno.tempo.co/read/1268528/visualisasi-data-mengubah-lautan-angkamenjadi-sumber-informasi (accessed Oct. 20, 2020).

[7] C. Amelia and P. Adi, "Reflecting design thinking: a case study of the process of designing dashboards," J. Syst. Inf. Technol., vol. 17, no. 3, pp. 286-306, Jan. 2015, doi: 10.1108/JSIT-03-2015-0018.

[8] R. Matheus, M. Janssen, and D. Maheshwari, "Data science empowering the public: Data-driven dashboards for transparent and accountable decision-making in smart cities," Gov. Inf. Q., vol. 37, no. 3, p. 101284, 2020, doi: 10.1016/j.giq.2018.01.006.

[9] D. Hirshleifer, Y. Levi, B. Lourie, and S. H. Teoh, "Decision fatigue and heuristic analyst forecasts," J. financ. econ., vol. 133, no. 1, pp. 83-98, 2019, doi: 10.1016/j.jfineco.2019.01.005.

[10] M. Fitrah and D. Luthfiyah, Metodelogi Penelitian | Penelitian Kualitatif, Tindakan Kelas \& Studi Kasus. Sukabumi: CV. Jejak, 2017.

[11] W. Purhantara, Metode Penelitian Kualitatif untuk Bisnis. Yogyakarta: Graha Ilmu, 2010.

[12] C. Narbuko, A. A. Achmadi, and Haji, Metodologi Penelitian. Jakarta: PT. Bumi Aksara, 2013.

[13] J. Noor, Metodologi Penelitian : Skripsi, Tesis, Disertasi, \& Karya Ilmiah. Jakarta: Kencana Prenada Media Group, 2011.

[14] U. Sekaran and R. J. Bougie, "RESEARCH METHODS FOR BUSINESS." Wiley, New York, 2016, [Online].

Available: https://search.ebscohost.com/login.aspx?direct=true\&scope=site \&db=nlebk\&db=nlabk\&AN=1639487.

[15] D. Dowding and J. Merrill, "The Development of Heuristics for Evaluation of Dashboard Visualizations," Appl. Clin. Inform., vol. 09, pp. 511-518, Jul. 2018, doi: 10.1055/s-0038-1666842.

[16] A. Cuttone, M. Petersen, and J. Larsen, Four Data Visualization Heuristics to Facilitate Reflection in Personal Informatics. 2014. 